\title{
Using picturebooks to develop critical visual literacy in primary schools: challenges of a dialogic approach
}

\section{Uta Papen, Lancaster University}

\section{Abstract}

This paper presents findings from a collaborative project on critical visual literacy in primary schools. In the project, we (a researcher and a teacher) implemented a series of picturebook discussions with children in years 5 and 6 . Our first aim was to develop the children's ability to analyse the visual images in picturebooks and how authors/illustrators use these, together with writing, to communicate specific ideas. The second aim was to promote a dialogic lesson (cf. Wells 2009) in which the children would lead the talk. In the paper, I discuss the challenges we faced in reaching our aims. My data includes observation notes, audiorecordings of the sessions and of discussions with the children. In the analysis, I examine the roles we took on, for example as extenders and clarifiers of the children's talk (Sipe 2008). However, unbeknown to us at the start, our two project aims turned out to be in conflict with each other. While the children enjoyed looking closely at the pictures and discussing the books' possible meanings, without repeated questions and prompts, they focussed on the book as story not on how it was constructed by the author and illustrator. This required a more teacher-focussed approach than what we had planned.

\section{Introduction}

In this paper I discuss findings from a collaborative project to support critical visual literacy in primary schools. In the project, we (a literacy researcher and a primary school teacher) used picturebooks to support primary school children's critical thinking about images and texts. Neither critical nor visual literacy are explicitly addressed in the statutory English primary curriculum (DoE, 2014). Along with other academics, we believe that in the contemporary world of communication, the ability to engage in a critical manner with different modes is essential to being literate (Luke, 2012, Serafini, 2012).

Our intention with this project was to support the children to be 'curious' and 'sceptical' reader-viewers (Luke, 1991: 143) who think carefully about the ideas presented to them in picturebooks and how authors and illustrators use different modes such as colour or size to 
present these. Dialogue - amongst the children and with the teacher - is a crucial part of critical literacy (Freire, 1972) and our aim was to support such dialogue. To achieve this, we set up a series of picturebook discussions with children in years 5 and 6 of primary school. In terms of research, the question guiding our project and also this paper is to examine what roles we as teachers took on in enabling dialogue and to what extent these roles supported our aims of critical visual literacy. In the analysis I examine in particular the challenges we faced to teaching critical visual literacy through a dialogical approach.

\section{Critical (visual) literacy}

Our project draws on theories of critical literacy and critical visual literacy. We base our work on ideas by Freire (1972), Luke and Freebody (1999), Janks (2014) and Comber (2015). Critical literacy, as these authors suggest, is a way of reading that involves not just seeking to grasp the text's meaning but to think more deeply about the ideas and values put forward by authors. Teachers who want to support children's critical literacy involve them in careful examinations of how texts are constructed, what perspectives they present, which ones they exclude and what effects on the reader authors and illustrators seek (Janks, 2014, Hope, 2018).

Critical visual literacy is a form of critical literacy that pays particular attention to the use of visual modes and how, together with writing, they create meaning. With regards to picturebooks, critical visual literacy includes looking carefully at both text and images and how they interact. Beyond this, critical visual literacy, very much like critical literacy, entails looking at how linguistic and visual means are used to convey the specific ideas, positions and biases contained in texts (Evans, 2015). This implies that if we want children to be critical reader-viewers, we need to engage them in discussions of how authors/illustrators use 
visual tools, for example colour or gaze, to present an idea or message (Serafini, 2012, Callow, 2017). Furthermore, to achieve critical visual literacy, children need to be encouraged to 'interrogate' (Serafini, 2012) what messages visuals convey: how these constrain what readers are invited to believe and what alternative readings could be considered. In this sense, critical visual literacy pursues the same aspirations as critical literacy, but extending these to modes beyond verbal language.

\section{Picturebooks and critical (visual) literacy}

Children's engagement with picturebooks has been widely researched. Arizpe and Styles (2016) provide a helpful overview of research in this area. Studies vary in the topics they explore (via the choice of picturebooks) and in their aims for children's learning, some privileging 'literary understanding' (Sipe, 2008a) or 'aesthetic development' (Doonan, 1993) others including aims such as critical thinking and visual analysis (see for example Callow, 2017, Roche, 2015). Many studies emphasize the importance of talk in children's engagement with picture books, highlighting the need for teachers to support children jointly exploring picture books (Arizpe et al., 2014, Evans, 2009, Lysaker and Sedberry, 2015). In our project we drew in particular on Roche's (2015) 'critical thinking and book talk' (CT\&BT), an approach that supports children's critical engagement with picturebooks through teacher-facilitated but child-focussed classroom talk.

\section{Critical literacy, book talk and dialogic teaching}

In critical literacy, teachers are facilitators of dialogue (Freire, 1972). In this role, the teacher is not the only person holding valid knowledge. In Roche's picturebook talks, the teacher uses 'open-ended comments and questions' $(2015: 112)$ to stimulate the children's thinking and to invite them to find explanations for their views. This approach has much in common 
with other strands of educational research and practice that explore the role of classroom discourse in supporting learning. These include 'dialogic teaching' (Lyle, 2008) and 'dialogic inquiry' (Wells, 2009). These approaches assert that learning in classrooms is nourished by interactions with others and by the ideas and assumptions students are exposed to through these interactions. Dialogic pedagogy favours collaborative forms of classroom interaction (Mercer and Dawes, 2011), where children take an active part in the construction of meaning. Dialogic teaching does, however, rely on the teacher as facilitator of dialogue (Lyle, 2008). In picturebook discussions, teachers may use specific question types, for example Roche (2015) suggests 'I wonder why' questions, while Labadie et al. (2012) speak about the use of 'purposeful prompts' to engage children in critical discussions of texts. Sipe (2008b) has identified different roles that teachers take on in picturebook discussions, for example 'manager' or 'encourager' He echoes the need for picturebook discussions to be participatory not teacher focussed. In this paper, I draw on Sipe, Roche and others to examine in detail the roles my co-researcher and I took on and whether these supported our project aims.

\section{Methodology}

The project was implemented between January and July 2017. Throughout this period we ran fortnightly reading sessions with children in year 5 (9 and 10 year olds) and year 6 (10 and 11 year olds).

The school is a small primary school located just outside of a medium-sized city in the northwest of England. Apart from the reception class, there are always two year groups in one class. The children's attainment is above the national average. The number of children for whom the school receives extra funding due to social disadvantage is below average. 
At each of my visits, we conducted two sessions, with the year 5 and the year 6 group. There were between 10-14 children in each group. All of the children had English as their first or main language. The sessions, held in the school hall or the dining hall, lasted about one hour. We always had two or three copies of the book so that everybody could see the text and images. First one of us read the book to the group. We then opened the discussion by using Roche's (2015) 'pass-the-tip' method: going round the circle, each child is invited to share their initial reactions to the book. When one child has spoken, they tap on their neighbour's shoulder to invite the next person to talk. After this, the discussion was primarily guided by the children's choices, although, as I will illustrate below, we also sought to prompt for specific issues to be looked at.

Ms R and I facilitated these sessions jointly. We chose books that deal with complex themes which we expected the children to be able to relate to. From the school's perspective it was important that the books were connected to the classes' termly and yearly curriculum themes.

The project was collaborative in the following sense: I had approached the school and discussed my idea with the head teacher and with Ms R. Ms R and I then discussed the general idea and aims and chose books. We both read Roche's book. Before the first session with the year 5 and 6 children, and about every 4 weeks throughout our work with them, Ms $\mathrm{R}$ and I spent time together to review previous discussions, choose new books and plan the forthcoming sessions.

I obtained ethics clearance for the study from my faculty's research ethics committee and parents consented to their children taking part in the project. All names of children used in the data extracts below are pseudonyms. 
The data consists of my observation notes, audio- and video-recordings of some of the sessions and my notes from my regular discussions with Ms R. For the purposes of this paper, I have carried out a thematic analysis of the transcripts of all the 10 audio-recorded circles. I began by reading the transcripts multiple times. In line with the research questions (see above) I specifically examined our, the teachers' interventions, how the children responded to these and how dialogue developed. I annotated the transcripts to highlight examples of different interactions and to identify parts of the talk that focused on the visual aspects of a book.

\section{Analysis: teachers' roles and the challenges of dialogical teaching for critical} visual literacy

Throughout the sessions, Ms R and I took on different - but overlapping - roles. In the following I discuss these roles and the extent to which they helped us achieve our goal of supporting the children's critical visual literacy while also offering child-led dialogue. As I will show, our two aims of supporting critical visual literacy and enabling a dialogic lesson were somewhat in conflict with each other and many of the difficulties we as teachers faced can be related to this.

\section{Extract 1}

Sipe (2008b: 387) suggests that in picturebook discussions such as ours, teachers act as 'managers' of the children's talk. Managing was a task we fulfilled throughout all sessions. It served to support the children's dialogue by making sure that all children were able to contribute, that they listened to each other's ideas and did not interrupt or talk over each other. But we also acted in a range of other roles. 
In the following extract, a group of year 6 children discuss a page from the book Angry

Arthur by Hiawyn Oram and Satoshi Kitamura. In the story, Arthur, the protagonist, becomes angry when his mother does not allow him to watch a western on TV but sends him to bed. In striking visual images, accompanied by short text, the book shows Arthur's growing anger and its consequences. In this extract, the children discuss whether what happened to Arthur is realistic or not. I have added, in bold, analytical comments which I discuss further below.

1 Paula: It's just really unrealistic, cos how did the bed stick to the piece of Mars floating

2 away. And also, how did he and the cat and everyone else survive without a space

3 helmet in space? Focus on story

$4 \quad \mathrm{U}: \mathrm{Mm}$.

5 Ms R: [....] Shall we think then about this idea of it being unrealistic and how is he 6 surviving in space with no space helmet? What's that telling us about the story? Go 7 on, John. Encourager; extender/refiner; director; authentic question

In line 1, Paula initiates the discussion of a picture showing Arthur - in his bed that sits on a piece of Mars, propelled into space by his anger - by declaring how unrealistic she thought this was. Paula focusses here on the story (not on how it is constructed), a point to which I will return later. In response, Ms R. affirms Paula's interest in the story's apparent lack of plausibility by repeating parts of her contribution. Ms R and I often repeated a child's comment, thereby affirming their view. Sipe (2008b: 386) speaks about teachers playing an important role as 'encouragers' of the children's discussions. This reflects our goal of facilitating the children's dialogue. In lines 5 and 6, Ms R affirms but also ‘extends' Paula's comment by turning it into an 'authentic question' (Lyle, 2008: 230) that she addresses to the children. Sipe uses the label 'extender/refiner' (Sipe, 2008b: 387), to capture the teacher's role in identifying parts of the children's conversation that, he suggests, could lead to 'teachable moments' where new ideas and insights can be shared. With her 'authentic question', Ms R took up what seemed to be a teachable moment - better described though as an opportunity for child talk and learning 
to happen - by inviting discussion. Authentic questions (what Roche calls open-ended questions) do not invite to recall known information but they request exploration and negotiation of an issue, the 'answer' not yet known and potentially multiple. This is line with the goals of dialogical inquiry (Wells 2009).

With her open-ended question Ms R does, however, seek to steer the discussion into a certain direction. She suggests that the children should look beyond a specific page at the wider story. This is another frequent role we took on: we invited the children to make links between different parts of the book and draw their attention away from a specific scene or a particular detail in a picture to consider the story's wider meaning and how this is communicated via text and image. This was a crucial role, in particular if the book, such as Angry Arthur, had much intriguing visual detail to offer which the children spent a lot of time looking at. I would describe this role as 'director' of the discussion. In this role, we pursued our aim of developing the children as critical visual readers. This is how the children reacted to Ms R's invitation to consider the wider story:

8 John: Maybe he's imagining what he could do if he was so angry, maybe.

9 Ms R: Right, he's imagining what he could do. Go on, Ellie, what do you think? Encourager; inviting others to join

10 Ellie: I think that um, oh yeh, um I think that he wasn't actually doing this stuff. It was

11 like just exaggerating to sort of like get the point across. Author considered (implicit)

12 Ms R: Oh like, what is the point that they're trying to get across? Extender; author/illustrator considered (implicit); authentic question

John's comment (line 8) shows him trying to make sense of the story. In line 9, Ms R repeats and thus acknowledges John's idea, but turns immediately to Ellie, who had raised her hand, and encourages her to join the discussion. Ellie's contribution (line 10) moves the discussion towards an - implicit - consideration of the author and illustrator who have created the story in this particular way. In her response, Ms R (line 12) takes up this perspective and turns it into 
another authentic question. This is also an invitation to think further (extension, in Sipe's words) about the story's message. Ms R does not in this moment explicitly invite comments from other children (to invite more dialogue amongst the children). But her question acts as a prompt to think about the author and illustrator, in line with the aims of critical visual literacy. Ellie responds:

13 Ellie: That he shouldn't really get angry because it was [??].

14 Ms R: Oh, you shouldn't get angry, it doesn't get you anywhere. Did it get him to watch 15 the TV? Encourager (affirming), director, closed question

16 Several children: No.

17 Ms R: [LAUGHS] No, great.

18 Hannah: I think it's actually, in a way it's very unrealistic that his grandma had a space 19 helmet, but no-one else did, but they were still surviving and- focus on story

In line 14, Ms R affirms Ellie's idea about the story's meaning. She then asks a question that invites others to pursue Ellie's line of thought. To prompt the children to think about the story's meaning, she 'directs' the children's talk towards to the narrative and the end of the story. She ends with a closed question. The children briefly respond. But in line 18, Hannah moves us back to attend to a specific detail in one of the pictures and to the question of how realistic this is. In the picture Hannah refers to, Arthur's anger had become an earth tremor that had propelled him and his grandmother into space. While he is floating around freely, dressed in his normal clothes, his grandmother is shown in a space suit. Hannah, looking at the picture from the vantage point of her own experience of the world, concludes that what is happening at this point in the story is highly unrealistic. Hannah focusses on the story. This is an example of a regular challenge we faced. The children responded to our prompts, but they also interjected their own ideas, thus curtailing a line of analysis that had just began. Here is how Ms R responds to Hannah's comments:

20 Ms R: Yeh, I wonder why they drew it like that. Why did Kitamura decide to draw the 21 grandma in a spacesuit? What do you think? Lily? Extender; authentic question; illustrator named 
22 Lily: Probably cos it was quite funny to sort of imagine a grandma in a spacesuit.

\section{Author/illustrator considered (implicit)}

$23 \mathrm{U}$ : It is funny isn't it, but why did he want to put in something funny in the book? Ellie?

\section{Extender; authentic question; illustrator considered (implicit)}

24 Ellie: Because it's such an angry story, you just want people to not like, reading it, you

25 want them to also laugh so it's not just boring. Illustrator considered (implicit)

26 U: Well that's interesting, yeh, yeh. Encourager (affirming)

In line 20, Ms R again acts as 'extender/refiner' when she identifies Hannah's contribution as an opportunity to draw the children's attention to the illustrator. Naming Kitamura, the illustrator, allows Ms R to return the children's discussion to an analysis of illustrator intentions and use of visual means. This prompts the children to move away from discussing the story as such and to consider the author or illustrator and their choices (see lines 22ff.). In line 20, Ms R uses Roche's (2015) 'I wonder why' question. She then rephrases her question and names the illustrator. Ms R's questions open up the floor for the children to consider different options. Ms R's question models 'exploratory talk', where questions invite the children to offer reasons for the ideas they have offered (Mercer, 2008), in our case about the illustrator's choices. Lily (line 22), who previously had not contributed to the talk, responds to Ms R's invitation and thinks aloud about the illustrator drawing the picture of Arthur and his grandmother in space (but not naming the illustrator explicitly). In line 23, I act as encourager, seeking to invite further discussion: I use an authentic (open-ended) question to invite the children to think about the illustrator's motifs. My question provokes a response that shows the children engaging in critical visual literacy: Ellie (line 24/25) alludes to the illustrator, who, she presumes, must be aware of what a reader might find attractive. Although Ellie does not name Kitamura we can see here an interaction where the children, supported by our questions, consider the illustrator and his intentions. Contrary to what they did at the beginning of the extract, here they do not focus on the story as such but on how it was constructed. I will return to this below in the discussion. 


\section{Extract 2}

The following is an extract from a discussion of the book The Colour of Home written by Mary Hoffman and illustrated by Karin Littlewood, held in early July with a group of 13 children in year 5. The book tells the story of a boy from Somalia who had to flee his home because of war, spent time in a refugee camp before arriving in his new school in England. In the extract below we were looking at the picture showing Hassan, the protagonist, on his first day in his new school. I ask the children about how Hassan might feel. Analytical comments are highlighted in bold.

1 Anna: He'll probably be really scared. Like, you know when you have that feeling

2 where you're really scared inside?

$3 \mathrm{U}$ : Yeh and even here perhaps arriving in the new school, maybe he just looks down

4 because he's scared and so he doesn't see that-. Maybe the children are even

5 smiling at him but he can't really see that because he's scared and worried and

6 doesn't really know. So at the end-[turning the children's attention to the last page

7 of the book], look, where does he look here? Fellow wanderer/seeker; director

In line 1 Anna responds to my question about how Hassan might feel. With my response, (lines 3-5), I briefly act as 'fellow wanderer/seeker', another of Sipe's (2008b) roles: I join in the children's explorations and think aloud about what Hassan might not see. The local pupils' faces are visible in the image, but only one of them can be seen to smile. While my contribution was intended to encourage the children's engagement with the book, it took floor time away from them rather than to invite their own 'wanderings' about this page. Instead, I could have used an authentic question to invite the children to look at Hassan's gaze and to prompt them to think about the illustrator's motifs. In line 7, I end my turn with a contribution that fits the idea of the teacher as director. I invite the group to look at Hassan's gaze at the beginning and the end of the book. Here is how the children respond:

8 Jake: Up to the ceiling.

9 U: Yes. Can you see that? Now he looks up, does he? And can you describe his face?

\section{Extender}


10 Lily: Happy.

$11 \mathrm{U}$ : He is smiling and happy, isn't he? So there is something that. Can you see the 12 illustrator, the person who, that must be Karin Littlewood. I think she must 13 have thought about that quite carefully, isn't it? But at the beginning she 14 showed him looking down and looking very sad. Look, there you kind of, well 15 there he's looking up a little bit but not really. Encourager; extender; illustrator named 16 Jake: Yeh, because someone's talking to him I think. $17 \mathrm{U}$ : Where is he looking here? Is he looking to something? Extender; clarifier/prober

Jake (line 8) responds to my question and in line 9 I affirm his contribution and seek to extend it with a further question. In line 12, following Lilly, I name the illustrator. I seek here to draw the children's attention to the illustrator as choosing specific semiotic means (here: gaze). However, instead of inviting the children's ideas about the illustrator's motifs, I offer my own ideas. I sought to 'model' here for the children how we can consider illustrator's choices when discussing a picturebook. In lines $14 / 15$, I then seek to invite the children to pursue this line of inquiry. We were looking at Hassan's face in the last picture of the book. Jake responds and offers a possible explanation for the direction of Hassan's gaze. My reaction to Jake, line 17, is a question that seeks, in Sipe's words, clarification, where the teacher takes up children's remarks, links them to each other and, as 'clarifier/prober', seeks further 'information or explanation and questioning' (Sipe, 2008b: 387). Mia and Ollie's responses (below, lines 18-21) illustrate the children responding to my probe in the way I had intended, offering more detailed comments on Hassan's gaze:

18 Mia: He's looking straight forward.

19 Ollie: He's looking at the picture on the wall.

20 Mia:- like he's-

21 Ollie: He's probably just thinking.

$22 \mathrm{U}$ : Oh yes he's looking at his own picture. Encouraging (no mention of illustrator) 23 Emily: -He looks really sad.

24 Anna: He might be remembering what happened, cos he looks quite upset, like 25 he just remembered what happened. Focus on story 
In line 21, Ollie then seeks an explanation for Hassan's gaze. In line 22, I again act as

encourager, repeating Ollie's earlier comment (line 19) on where Hassan looks at. I seek here to keep the children focused on discussing gaze. But I do not prompt again for the illustrator. Emily and Anna's reaction (lines 23-25) to my intervention shows them seeking to understand Hassan's feelings. This, clearly, is what they are interested in here. They no longer refer to the illustrator nor do they consider the protagonist's gaze. In other words, they take the discussion away from analysing the illustrator's use of gaze (an element of critical visual literacy). It is noticeable that throughout the exchange in extract 2 I am closely involved in the talk, using focussed interventions and modelling to frame the children's talk within what is revealed to be my preoccupation: the illustrator's use of gaze. However, despite my interventions, the children return their attention back to the story. Anna tries to imagine Hassan's feelings.

\section{Discussion}

The two extracts illustrate several of the roles Ms R. and I took on and how the children responded to our interventions. Sipe's roles were a useful starting point for this discussion. My analysis suggests that the positions of manager, encourager as well as extender/refiner are indeed crucial if teachers want to facilitate critical discussions of picture books. The role of clarifier/prober seemed to overlap with the desire to extend and refine. As teachers, we probed to seek clarification as well as to develop extensions of an idea. I also identified the role of director (not mentioned by Sipe), was particularly important because it helped to focus the children's talk on the relations between different pages and pictures, in doing so, to achieve a more critical examination of how author/illustrator used visual means to create the story and convey ideas. Directing though, as the word suggests, implies actively steering the talk and suggests strong teacher presence. 
Looking at our roles, we can see that the aim of facilitating a child-led discussion was not always easy to achieve. Looking at the above discussion, I conclude that some of the challenges we experienced are due to our two project aims requiring different kinds of roles for us. To introduce the children to critical visual analysis, our prompts and 'directions' were required and, as a result, we took on a prominent role in the discussions (see extract 2 in particular). For the talk to be child-centred, however, we needed to act mainly as facilitators, not as directors and to let the children take the lead.

Our teachers' voices were strongly present in parts of the sessions. When we repeated or rephrased a child's comment, this was an implicit evaluation. Roche (2015) advises against teachers evaluating children's contributions to critical book talk. However, we were aware that our sessions were a new type of lesson for the children. When a child contributed, we wanted to affirm and encourage them as a participant in this new lesson. Inadvertently though this led to a dialogic structure focussed on one child and one of us. Both extracts show that we often missed opportunities to invite others to contribute and for the children to address their comments to each other not to us. For example, in extract 1, line 12, Ms R invites further comment on what Ellie has suggested. But she does not explicitly invite other children to speak and so it is Ellie who talks again. Or, in line 23, responding to Lily, I could have asked the other children to comment on her idea.

In a long term project on making classrooms more dialogical, Wells and Arauz (2006) found that it took time for teachers to get used to abstaining from the common practice of following-up on a child's contribution, instead inviting other children to comment on the student's idea. The above extracts show that Ms R and I often provided feedback to a child's intervention where we could have asked other children to do so. Wells and Arauz' (2006) study also showed that the most important factor in teachers supporting children's dialogue and joint explorations of issues was the extent to which the teacher's questions called for 
multiple possible answers and thus invited negotiations. Our questions did not always do that. For example, in extract 1, line 21, an authentic question produced further discussion. But in extract 2, lines 12 ff., I did not ask such a question.

Introducing the children to critical visual literacy required our interventions. Looking at all our sessions, including those examined here, we can see that the children focussed much of their attention on the 'text as story' (Unsworth and Macken-Horarik, 2015: 66): they tried to make sense of the story's characters and narrative development. Farrar (in Arizpe and Styles, 2016: 160) calls this a focus on 'story-as-subject'. Examples are extract 1, line 1 (Paula) and line 18 (Hannah) and extract 2, lines 24/25 (Anna). Looking at our data, this is the step that our children engaged with enthusiastically and in depth, with us as managers of their talk.

However, while we agree with previous researchers that the focus on the story is an important part of children's engagement with picturebooks (Arizpe and Styles, 2016, Roche, 2015), in line with our understanding of critical visual literacy, we wanted to invite the children to think about how 'specific visual or textual features may be linked to an author's purposeful choice to shape the reader's view' (Callow, 2017 :234). In other words, we wanted them to think about 'the text as construct' (Unsworth and Macken-Horarik, 2015: 66) and to focus on the picturebook as 'object' of analysis (Farrar, in Arizpe and Styles, 2016: 160).

Discussions of author/illustrator intensions and use of semiotic modes did take place, but similar to what happened in extract 2 , the children often returned to focus on the story, or, to a specific detail in the pictures. When we prompted for author and illustrator, the children responded but a single prompt did not necessarily lead to an in-depth discussion of illustrator decision and semiotic choices. Therefore, to support this type of analysis, we had to steer the discussion more strongly and we had to demonstate a specific way of examining and talking about the pictures. We also met with the children's resistance. I recall another moment in the 
discussion of Angry Arthur when I had wanted them to look at the illustrator's use of the colour white in relation to Arthur's anger. I prompted repeatedly but ultimately 'gave up', saying to the group that I could see that they had had enough of talking about colour. Our concern here and in other situations was that we did not want the session to have interactive pattern that was contrary to our belief in the importance of the children learning through their talk. Yet, giving more room to the children's own ideas meant that we had to accept limitations similar to those other teachers have described. Smith for example concludes that her desire for the two boys she worked with 'to be able to see through the texts and notice how they are achieved' (2009: 95) was only partly fulfilled. Åberg and Olin-Scheller (Åberg and Olin-Scheller, 2018) show that in their lessons on critical literacy, when the teacher did not intervene, the students talk remained framed by their established opinions and critical literacy was therefore limited.

A related issue here is that given the constraints of the curriculum and which aspects of literacy it privileges it is reasonable to assume that the children were not used to lessons requiring them to explicitly analyse picturebooks from the point of view of their creator. Their everyday interactions with texts are unlikely to involve the kind of sustained and questioning reading-viewing that we invited them to engage in (Smith, 2009). The two extracts show that when the children spoke about the author or illustrator, they tended to do so implicitly (see for example extract 1 , lines 23/24). This suggests that the children recognised authorial choices but that to discuss these explicitly was new to them. To encourage this, as Farah suggests (2016), Ms R and I could have named the author and illustrator when discussing semiotic choices, something we did, however, not always do. 
What could we have done differently and how could teachers offer sessions that more successfully develop critical visual literacy through dialogic teaching? The main conclusion I draw is that our sessions could have benefitted from more explicit teaching about readingviewing but that this instruction should have preceded the picturebook discussions. Teachers pursuing aims similar to ours could start with short lessons covering visual theory, illustrating how each feature of a picturebook is a product of the author/illustrator choosing semiotic resources (Pantaleo, 2017, Serafini, 2009, Smith, 2009). These lessons would include teacher modelling of the kind I did in extract 2, seeking to equip the children with 'a language to describe and analyse how various modes inform and persuade readers' (Callow, 2017: 231), a key part of critical literacy. In a second step, teachers could then organise sessions similar to those we ran in our project, focussing on how to enable dialogue and critical discussions with them in the roles of manager, encourager, extender and director, but from a position of facilitating child talk. Any initiative of this kind does, however, need to accept that to develop critical visual literacy needs time (Labadie et al., 2012) and intervention beyond a short-term project such as ours.

Acknowledgements: I would like to thank the United Kingdom Literacy Association for supporting this study. I am very grateful to the school, my co-researcher and her colleagues and to the children who took part in our circles for making this research possible. I learned a lot and greatly enjoyed working with them.

\section{References:}

ÅBERG, M. \& OLIN-SCHELLER, C. 2018. Wolf cries: on power, emotions and critical literacy in firstlanguage teaching in Sweden. Gender and Education, 30, 882-898. 
ARIZPE, E., BAGELMAN, C., DEVLIN, A. M., FARRELL, M. \& MCADAM, J. E. 2014. Visualizing Intercultural Literacy: Engaging Critically with Diversity and Migration in the Classroom through an Image-Based Approach. Language and Intercultural Communication, 14, 304321.

ARIZPE, E. \& STYLES, M. 2016. Children reading picturebooks., London, Routledge.

CALLOW, J. 2017. "Nobody Spoke Like I Did": Picture Books, Critical Literacy, and Global Contexts. Reading Teacher, 71, 231-237.

COMBER, B. 2015. Critical Literacy and Social Justice. Journal of Adolescent and Adult Literacy, 58, 362-367.

Department of Education. 2014. The national curriculum in England. London.

DOONAN, J. 1993. Looking at pictures in picture books, Woodchester, Thimble Press.

EVANS, J. 2009. Introduction: it isn't enough to just read a book, one must talk about it as well. In: EVANS, J. (ed.) Talking beyond the page. London: Routledge.

EVANS, J. 2015. Could this happen to us? In: EVANS, J. (ed.) Challenging and controversial picture books. London: Routledge.

FREIRE, P. 1972. Pedagogy of the oppressed, Harmondsworth, Penguin.

HOPE, J. 2018. "The Soldiers Came to the House": Young Children's Responses to The Colour of Home. Children's Literature in Education, 49, 302-322.

JANKS, H. 2014. Critical Literacy's Ongoing Importance for Education. Journal of Adolescent \&amp; Adult Literacy, 57, 349-356.

LABADIE, M., WETZEL, M. M. \& ROGERS, R. 2012. Opening Spaces for Critical Literacy: Introducing Books to Young Readers. The Reading Teacher, 66, 117-127.

LUKE, A. 1991. Literacies as Social Practices. English Education, 23, 131-147.

LUKE, A. 2012. Critical Literacy: Foundational Notes. Theory Into Practice, 51, 4-11.

LUKE, A. \& FREEBODY, P. 1999. Further Notes on the Four Resources Model [Online]. Available: http://kingstonnetworknumandlitteam.wikispaces.com/file/view/Further+Notes+on+the+Fo ur+Resources+Model-Allan+Luke.pdf [Accessed 23.6.2017 2017].

LYLE, S. 2008. Dialogic Teaching: Discussing Theoretical Contexts and Reviewing Evidence from Classroom Practice. Language and Education, 22, 222-240.

LYSAKER, J. \& SEDBERRY, T. 2015. Reading Difference: Picture Book Retellings as Contexts for Exploring Personal Meanings of Race and Culture. Literacy, 49, 105-111.

MERCER, N. 2008. Talk and the Development of Reasoning and Understanding. Human Development, 51, 90-100.

MERCER, N. \& DAWES, L. 2011. The value of exploratory talk. In: MERCER, N. \& HODGKINSON, S. (eds.) Exploring talk in school. London: Sage.

PANTALEO, S. 2017. Critical thinking and young children's exploration of picturebook artwork. Language and Education, 31, 152-168.

ROCHE, M. 2015. Developing children's critical thinking through picture books, London, Routledge.

SERAFINI, F. 2009. Understanding visual images in picturebooks. In: EVANS, J. (ed.) Talking beyond the page. London: Routledge.

SERAFINI, F. 2012. Expanding the four resources model: reading visual and multi-modal texts. Pedagogies: An International Journal, 7, 150-164.

SIPE, L. R. 2008a. Storytime: young children's literary understanding in the classoom, New York, Teachers College Press.

SIPE, L. R. 2008b. Young children's visual meaning making in response to picture books. In: FLOOD, J., HEATH, S. B. \& LAPP, D. (eds.) Handbook of research on teaching literacy through the communicative and visual arts. second ed. New York: Routledge.

SMITH, V. 2009. Making and breaking frames. In: EVANS, J. (ed.) Talking beyond the page. London: Routledge. 
UNSWORTH, L. \& MACKEN-HORARIK, M. 2015. Interpretive responses to images in picture books by primary and secondary school students: Exploring curriculum expectations of a 'visual grammatics'. English in Education, 49, 56-79.

WELLS, G. 2009. Dialogic inquiry as collaborative action research. In: NOFFKE, S. E. \& SOMEKH, B. (eds.) The Sage handbook of educational action research Los Angeles: Sage.

WELLS, G. \& ARAUZ, R. M. 2006. Dialogue in the Classroom. Journal of the Learning Sciences, 15, 379-428.

\section{Picturebooks:}

Browne, Anthony (1994) Zoo. London: Red Fox Picture Books.

Hoffman, Mary and Littlewood, Karin (1993) The Colour of Home. London: Frances Lincoln Picture Books.

Oram, Hiawyn (2008) Angry Arthur London: Andersen Press Ltd.

Sheldon, Dyan (1993) the Whales' Song. London: Red Fox Picture Books. 